\title{
Analytical study of reduced beam sections under monotonic load
}

\author{
Cintantya Budi Casita ${ }^{1}$, Zetta Rasullia Kamandang ${ }^{1}$ \\ ${ }^{1}$ Universitas Pembangunan Nasional "Veteran” Jawa Timur \\ cintantyabudi.ts@upnjatim.ac.id
}

\begin{abstract}
This paper presents the result of three different type of reduced beam sections (RBS): radius cut, straight cut, and tapered cut under monotonic load using finite element analysis. Load is applied monotonically and divided into 9 steps, start from $500 \mathrm{~N}$ to $4500 \mathrm{~N}$, which increasing $500 \mathrm{~N}$ for each step, continuously. The dimension for the beam is WF $500 \times 200 \times 10 \times 16$ is used for those three types of RBS. The results show that radius cut gives better performance than the other two types. Stress distribution, load-stress curve, and loaddisplacement curve of those three types of RBS are compared as the result, then lead to the conclusion that the most effective connection amongst those three types of RBS above is RBS with Radius Cut.
\end{abstract}

\section{Introduction}

Strong column and weak beam concept must be fulfilled when designing earthquake resistant structure. As the name implies, the plastic hinge should occur in the beams prior to the columns [1][2]. One of the ways to weakening the steel beam flanges is using Reduced Beam Sections (RBS), furthermore strong column and weak beam requirement is satisfied. The RBS connection is one of the most popular connections due to their effectivity in reducing the stress concentration at the connection [3][4] and [5]. The use of RBS has many advantages as a steel moment connections due to their seismic ductility by relocated plastic hinge away from the column face [6][7][8] and [9]. Some of RBS types were proposed: RBS with Radius Cut, RBS with Straight Cut, and RBS with Tapered Cut [9]. FEMA-350 [9] and AISC-358 [10] can be referred as guidelines for designing RBS connection. The purpose of this paper is to explain the behavior of those RBS types above.

\section{Proposed connection details}

The dimension of the beam are provided in Table 1.

Table 1. Details of model

\begin{tabular}{cccc}
\hline Model & Beam size & $\begin{array}{c}\text { fy } \\
(\mathrm{MPa})\end{array}$ & $\begin{array}{c}\mathrm{fu} \\
(\mathrm{MPa})\end{array}$ \\
\hline Radius Cut & & & \\
Straight Cut & WF 500x200x10x16 & 250 & 410 \\
Tapered Cut & & & \\
\hline
\end{tabular}




\section{ICATECH ITATS $=$ =}

The $1^{\text {st }}$ International Conference on Advanced Engineering and Technology - 2018

Figure 1 below shows three different types of RBS: RBS with Radius Cut, RBS with Straight Cut, and RBS with Tapered Cut that will be analyzed.

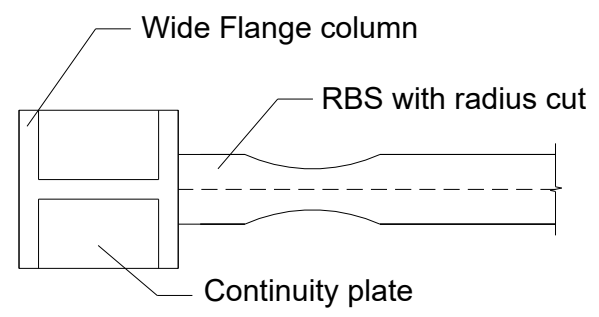

(a)

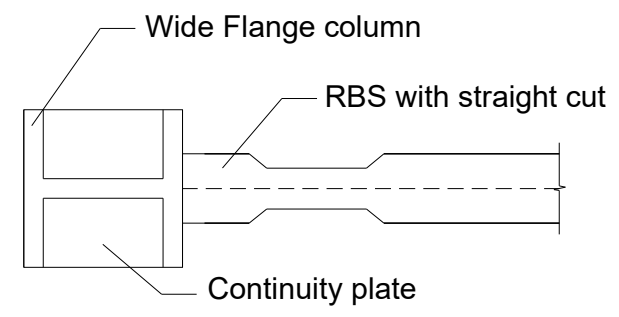

(b)

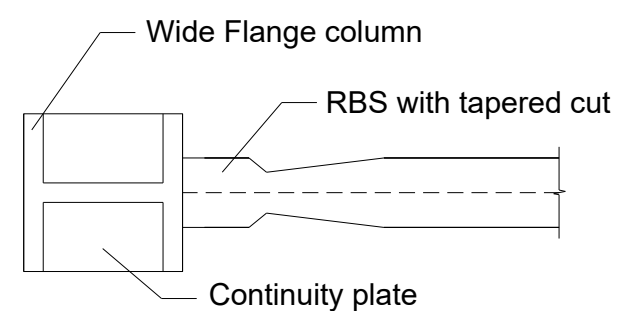

(c)

Figure 1. Top view of the RBS (a) with radius cut, (b) with straight cut, (c) with tapered cut

\section{FEM analysis}

\subsection{Material properties}

The elastic properties, Young Modulus $E$ and Poisson's ratio $v$ were set to be $200000 \mathrm{MPa}$ and 0.3 , respectively. For plastic properties is using stress-strain relationship formula [11].

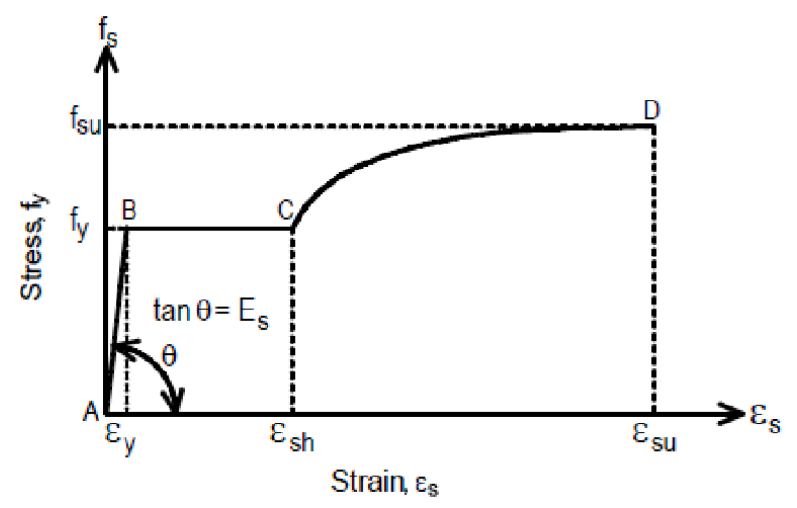

Figure 2. Stress-strain relationship of steel

A-B Region $\left(\varepsilon_{s} \leq \varepsilon_{y}\right)$

$$
\begin{aligned}
\varepsilon_{y} & =\frac{f y}{E s} \\
f s & =\varepsilon_{s} . E s
\end{aligned}
$$

B-C Region $\left(\varepsilon_{y} \leq \varepsilon_{s} \leq \varepsilon_{s h}\right)$

$$
\begin{aligned}
& f_{s}=f y \\
& \varepsilon_{s h}=16 . \varepsilon_{s h}
\end{aligned}
$$




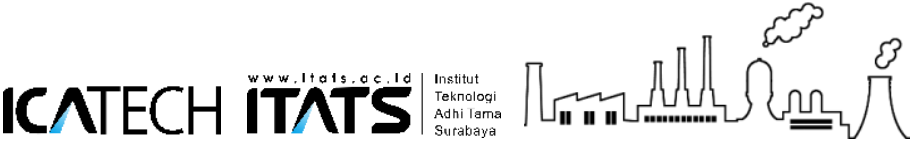

The $1^{\text {st }}$ International Conference on Advanced Engineering and Technology - 2018

C-D Region $\left(\varepsilon_{s h} \leq \varepsilon_{s} \leq \varepsilon_{s u}\right)$

$$
\begin{aligned}
& f_{s}=f y\left[\frac{m\left(\varepsilon_{s}-\varepsilon_{s h}\right)+2}{60\left(\varepsilon_{s}-\varepsilon_{s h}\right)+2}+\frac{\left(\varepsilon_{s}-\varepsilon_{s h}\right)(60-m)}{2(30 r-1)^{2}}\right] m=\frac{(f s u-f y)(30 r-1)^{2}+60 r-1}{15 r^{2}} \\
& \varepsilon_{s u}=\varepsilon_{s h}+0.14 \\
& r=\varepsilon_{s u}+\varepsilon_{s h}
\end{aligned}
$$

Table 2. Stress-strain value of steel (fy $250 \mathrm{MPa}$ )

\begin{tabular}{ccc}
\hline $\begin{array}{c}\text { Stress } \\
(\mathrm{MPa})\end{array}$ & Strain & $\begin{array}{c}\text { Plastic } \\
\text { Strain }\end{array}$ \\
\hline 0 & 0 & \\
250 & 0.00125 & 0 \\
250 & 0.02 & 0.018 \\
303.87 & 0.03 & 0.028 \\
358.013 & 0.05 & 0.048 \\
383.55 & 0.07 & 0.068 \\
397.09 & 0.09 & 0.088 \\
404.48 & 0.11 & 0.108 \\
408.30 & 0.13 & 0.128 \\
409.83 & 0.15 & 0.148 \\
410 & 0.16 & 0.158 \\
\hline
\end{tabular}

\subsection{Boundary condotion and loading}

In this model, the beam end is fixed to represent the rigid connection between the beam and the column. The load $F$ is applied to the other beam end monotonically. The amount of monotonic loads are provided in Table 3.

Table 3. The amount of monotonic load

\begin{tabular}{cc}
\hline Step & Load $(\mathrm{N})$ \\
\hline 1 & $5 \times 10^{2}$ \\
2 & $10^{3}$ \\
3 & $1.5 \times 10^{3}$ \\
4 & $2 \times 10^{3}$ \\
5 & $2.5 \times 10^{3}$ \\
6 & $3 \times 10^{3}$ \\
7 & $3.5 \times 10^{3}$ \\
8 & $4 \times 10^{3}$ \\
9 & $4.5 \times 10^{3}$ \\
\hline
\end{tabular}




\section{ICATECH ITAT'S}

The $1^{\text {st }}$ International Conference on Advanced Engineering and Technology - 2018

\subsection{Analysis FEM results}

\subsubsection{Stress distribution}

The stress dsitribution of three types of RBS are shown in Figures 3.

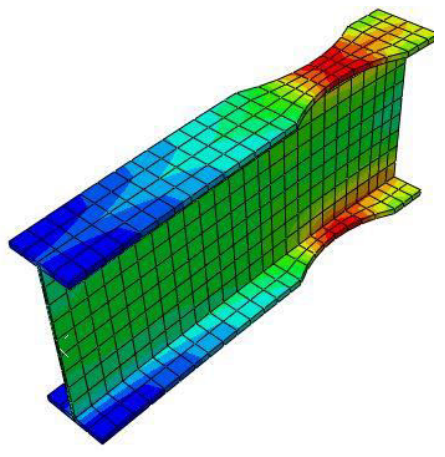

(a)

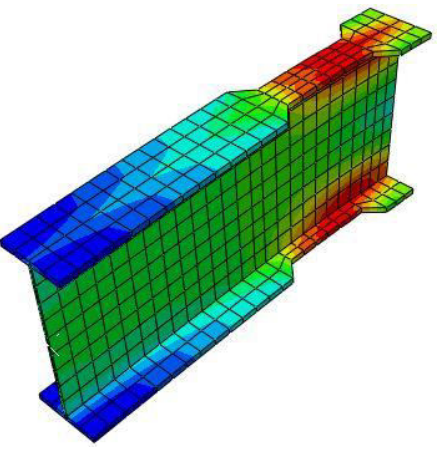

(b)

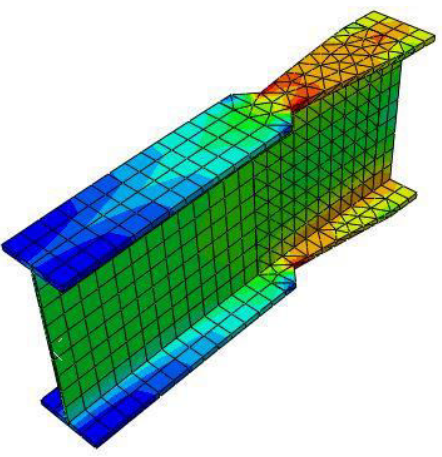

(c)

Figure 3. Stress distribution (S Mises) of RBS with (a) radius cut (b) straight cut (c) tempered cut on the first yield

According to the Figure 3 above, stress distribution of RBS with Tapered Cut shows that the first yield occures at the re-entrant corners.

\subsubsection{Load - Stress Curve}

Figure 4 shows comparison of the load - stress curve amongst three types in Figure 3. It showed that Stress (MPa) is directly proportional to Load (N). In RBS with Straight Cut, the first yield occures when $3000 \mathrm{~N}$ load is applied. Otherwise, the first yield in RBS with Radius Cut and Tapered Cut occures when $3500 \mathrm{~N}$ load is applied.

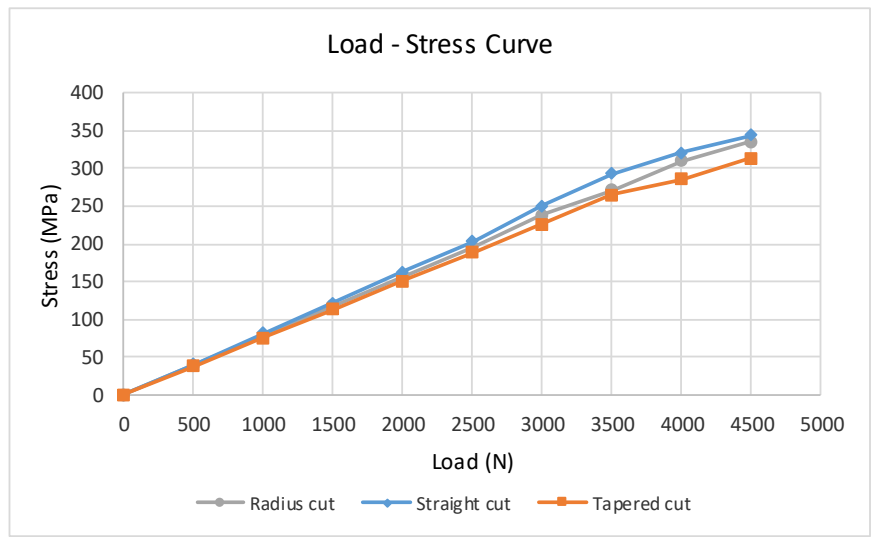

Figure 4. Load - stress curve

\subsubsection{Load - Displacement Curve}

Figure 5 shows comparison of the load - stress curve amongst three types in Figure 3. It showed that Displacement $(\mathrm{mm})$ is directly proportional to Load (N). Compared to RBS with Radius Cut and RBS with Tapered Cut, the largest displacement occures in RBS with Straight Cut. 


\section{KATECH ITATS}

The $1^{\text {st }}$ International Conference on Advanced Engineering and Technology - 2018

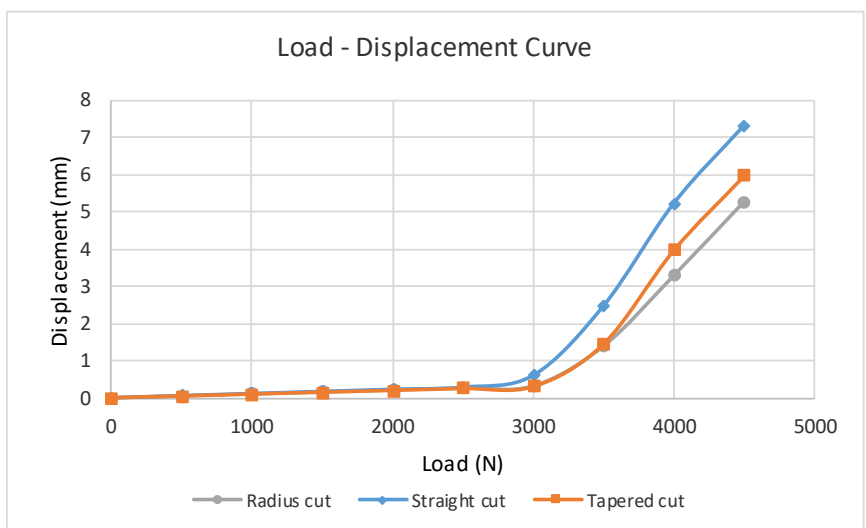

Figure 5. Load - displacement curve

\section{Conclusion}

According to the analysis above, following conclusions can be drawn:

1. Stress distribution of RBS with Tapered Cut shows that the first yield occures at the re-entrant corners which lead to fracture on the beam flange.

2. The first yield occures in RBS with Straight Cut earlier than RBS with Radius Cut and RBS with Tapered Cut when the load is applied monotonically.

3. The RBS with Radius Cut has the smallest amount of displacement. So, this type of RBS can reduces the amount of the inter-story drift of building structures.

4. The RBS with Radius Cut is the most effective connection amongst those three types of RBS above.

\section{References}

[1] J. C. M. Ho and H. J. Pam, "Inelastic design of low-axially loaded high-strength reinforced concrete columns," vol. 25, no. January 1995, pp. 1083-1096, 2003.

[2] M. Di Ludovico, M. Polese, M. Gaetani, A. Prota, and G. Manfredi, "A proposal for plastic hinges modification factors for damaged RC columns," Eng. Struct., vol. 51, pp. 99-112, 2013.

[3] K. Kildashti, R. Mirghaderi, I. M. Kani, and K. K. E. T. Al, "PL(A)98-238-379(Dauwe).pdf," vol. 2012, no. June, pp. 68-76, 2012.

[4] D. V. P. Rao and S. R. S. Kumar, "RHS beam-to-column connection with web opening parametric study and design guidelines," vol. 62, pp. 747-756, 2006.

[5] S. Wilkinson, G. Hurdman, and A. Crowther, "A moment resisting connection for earthquake resistant structures," vol. 62, pp. 295-302, 2006.

[6] N. Iwankiw and J. Hughes, "Dogbone : a new idea to chew on," no. February, 2016.

[7] S. Chen, C. Yeh, and J. Chu, "Ductile steel beam-to-column connections for seismic resistance," J. Struct. Eng., vol. 122, pp. 1292-1299, 1996.

[8] A. Zekioglu, H. Mozaffarian, K. L. Chang, and C. M. Uang, "Designing after Northridge," Mod. Steel Constr., vol. 37, no. 37(3), pp. 36-42, 1997.

[9] Federal Emergency Management agency (FEMA), "State of the art report on connection performance," no. 355D, pp. 1-305, 2000.

[10] American Institute of Steel Construction, "Prequalified Connections for Special and Intermediate Steel Moment Frames for Seismic Applications," no. AISC/ANSI 358-16, 2006.

[11] R. Park and T. Paulay, "Reinforced Concrete Structure," in A Wiley-Interscience Publication, New York, 1975. 